\title{
Bundle Pricing Decisions for Fresh Products with Quality Deterioration
}

\author{
Yan Fang, ${ }^{1,2}$ Yiping Jiang $\mathbb{D},{ }^{3}$ and Xingxing Han $^{2}$ \\ ${ }^{1}$ School of Economics and Management, Southeast University, Nanjing, Jiangsu 211189, China \\ ${ }^{2}$ School of Business, Dalian University of Technology, Panjin, Liaoning 124221, China \\ ${ }^{3}$ Department of Management Engineering, Nanjing Agricultural University, Nanjing, Jiangsu 210031, China
}

Correspondence should be addressed to Yiping Jiang; ypjiang@njau.edu.cn

Received 29 September 2017; Accepted 6 December 2017; Published 18 January 2018

Academic Editor: Chunming Shi

Copyright (C) 2018 Yan Fang et al. This is an open access article distributed under the Creative Commons Attribution License, which permits unrestricted use, distribution, and reproduction in any medium, provided the original work is properly cited.

\begin{abstract}
How to sell fresh products quickly to decrease the storage cost and to meet customer quality requirement is of vital importance in the food supply chain. Bundling fresh products is an efficient strategy to promote sales and reduce storage pressure of retailers. In this paper, we consider the bundle pricing decisions for homogeneous fresh products with quality deterioration. The value of fresh products with quality deterioration is approximated as an exponential function based on which customer's reservation prices are calculated. A nonlinear mixed integer programming model is used to formulate the bundle pricing problem for fresh products. By adding auxiliary decision variables, this model is converted into a mixed integer linear program. Numerical experiments and sensitive analysis are conducted to provide managerial insights for bundling fresh products with quality deterioration.
\end{abstract}

\section{Introduction}

A fresh product is an item that continues to deteriorate over time and causes its quality and value to diminish, such as fruits, vegetables, seafood, and meat. The market for fresh products has been expanding for years and became an important part of economic development. For example, in China, the scale of fresh product retailers has been increasing with the rate of $15 \%$ every year and has reached to 1,300 billion in 2016, which accounts for $52 \%$ of the total agriculture output [1]. However, the biochemical and physiological changes lead to the qualitative and quantitative deterioration of the fresh products, which accounts for a great amount of losses to consumers and retailers. Statistic results show that the quantity loss rate of fresh fruits and vegetables reaches up to $20 \%$ in China [2]. The cost of unsold products before their sell-by-date is estimated to be billions of dollars each year [3]. Consequently, how to sell fresh products quickly to decrease the storage cost and meet customer quality requirement is of vital importance in the fresh product supply chain and is a current managerial concern as well as an important research issue.
Bundling fresh products is an efficient way to promote selling of fresh products. It means selling two or more fresh products together in one united price [4]. From the practical perspective, bundling strategy provides an efficient method to achieve business objectives and has been proven in many industries, for example, grocery retailers [5], television providers [6], and holiday packages [7]. From the theoretical perspective, bundling strategy gives a novel viewpoint to consider how to improve the social surplus in the area of fresh product operations management. Firstly, bundling could attract more consumers by a lower-price. For example, when the peach is sold at a price of 2 dollars per pound, the bundle will be sold at 3 dollars with two pounds together. Secondly, bundling can reduce the storage by accelerating the selling speed of fresh products. Finally, bundling can enrich the quality control theory through bundling promotion for those fresh products with potential of spoilage.

However, the decision for bundling fresh products is not easy. The main reason is because the change of the qualitative and quantitative deterioration in fresh products will lead to the decrease on the value perceived by consumers [8]. The food quality has always played an important role in the retail 
process since it has been considered as a direct factor to influence a consumer's purchase decision [9]. Since everyone prefers a fresher product, the price has to be in accordance with the freshness of the products. Otherwise, the bundle will lose its attractive power to the consumer. Consequently, it is difficult to decide a bundle with the right amount, at a very appropriate price and on the right time, to maximize the retailers profit when the quality demands of the consumers are satisfied. Only when the profit of bundling is higher than that of unbundling does the strategy have managerial meanings.

In this paper, we consider the bundle pricing decisions for fresh products with quality deterioration. We consider the bundle of homogeneous fresh products. The value of fresh products with quality deterioration is approximated as an exponential function based on which the customer's reservation prices are calculated. A nonlinear mixed integer programming model is used to formulate the bundle pricing problem for fresh products. By adding auxiliary decision variables, this model is converted into a mixed integer linear program and solved by CPLEX. Numerical experiments and sensitive analysis are conducted to provide managerial insights for bundling fresh products with quality deterioration.

\section{Literature Review}

Our research is most related to two streams of literature, namely, research on the bundle pricing problem and on the problem of pricing for products with deterioration. In this section, we will review the related academic work from the following two areas.

(1) Bundle Pricing Problem. The composition and pricing of bundles have been widely studied. Bundle sells can eliminate the heterogeneity of customers and extract customer surplus in order to achieve economic and marketing goals [4]. There are two streams of bundle pricing literature. The first stream is from the strategic level to bundle a typical kind of products, for example, information product [10] and food product [11]. Managerial insights are provided from the strategic level. The second stream is from the operational level with focus on how to give an optimal scheme of pricing and composition of bundles. The mostly used methods are probability model [12], Bayes model [13], and MILPs (Mixed integer linear programs) [14]. MILPs are efficient when the number of products is large [15]. A mixed integer linear programing model was proposed by Hanson and Martin (1990) [14] to address the bundle and pricing problems for the first time. Then some academic work extended the model to adapt to new problems. For example, Jiang et al. (2011) [5] proposed a multistage online bundle method, and Mayer et al. (2013) [7] considered the bundle problem with capacity constraints. Wu et al. [16] studied the customized bundle under which consumers decide on the composition of the bundle while the seller determines the size and price of the bundle. And the cardinality of the set of solutions increases linearly with the number of single products [7]. However, when the marginal costs of products are high and different from each other, the customized bundle cannot be implemented.

(2) Pricing for Products with Deterioration. Recently, significant researches combine pricing for perishable products with quality deterioration. We review this part from the demand representation, decisions on pricing and deterioration inventory, and dynamic pricing methods. Firstly, one of the issues in pricing perishable product is to measure the time-and-price sensitive demand, and reference price effect is the mostly used method. For example, Hardie et al. (1993) demonstrated that differences between observed and reference quality can significantly affect purchase probabilities [17] through empirical study. Dye and Yang (2016) modeled the deteriorating goods pricing strategy with reference price effects [18]. Secondly, a great number of models have been proposed to investigate the deterioration inventory. For example, Qin et al. (2014) consider the pricing and lot-sizing problem when the quantity of fresh products is deteriorating simultaneously [3]. Bai and Kendall (2008) assume that the demand rate is dependent on the displayed inventory and the freshness of an item, but the deterioration of freshness is not connected with the deterioration characteristics of fresh produce [19]. Finally, dynamic pricing is the mostly used method for perishable produce for its flexible response to the real-time demand. For example, Wang and Li (2012) presented a dynamic pricing model with accurate quality indicator to maximize food retailer's profit and reduce food spoilage waste [20]. Liu et al. (2015) formulate a joint dynamic pricing and preservation model for perishable foods from selling a given initial inventory of food [9].

The existing findings provide some fundamental elements for our research. Due to the characters of the bundle pricing problem with quality deterioration, the following work has to be studied in this research. Firstly, how to approximate the value of bundles consisting multiple fresh products with quality deterioration. Secondly, when multiple products and time periods are considered, how to formulate the problem is worth further study. Our research aims to bridge the gaps in current literature by approximating the time related value of fresh product bundles, and by providing a mixed integer nonlinear programming model to bundle homogeneous fresh products with quality deterioration. These findings can provide operational tools for the grocery retailer to make pricing strategy and carry out the inventory and promotion activities on agriproducts.

\section{Problem Description and Formulation}

3.1. Problem Descriptions. In this section, we formulate the optimal bundling and pricing problem for a fresh product with quality deterioration. We consider one kind of fresh product. The model is formulated from the seller's (he) perspective who provides one kind of fresh product to consumers (she) within the life cycle. For example, a fruit retailer provides peaches to consumers. Due to the quality deterioration of peaches, the retailer decides to bundle multiple units of peaches from the second day at a lower unit price as shown in Figure 1. The retailer is faced with the 


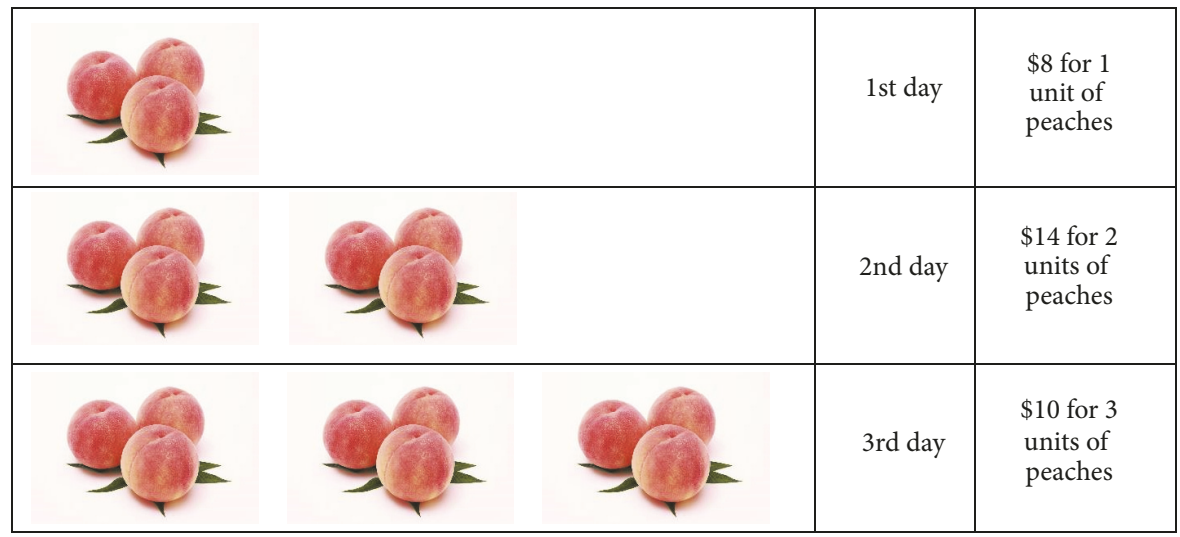

FIgURE 1: An example of bundling fresh products.

problem to decide how many units of goods to be included in a bundle at a specific time, and how to price these bundles to maximize its profit while consumers maximize their surplus. The basic assumption and notations are as follows.

(1) Number of Potential Consumers I, Bundle J, and Life Cycle Time $T$. We assume the number of potential consumers is $I$ with index of $i$. It could be estimated by the historical data in reality. The number of potential bundles is $J$, with index of $j$ to represent for the number of items included in a bundle. The life cycle time of the fresh product is defined as $T$ with index of $t$, which begins from 1 . At the beginning of each time period, the retailer needs to decide a preferred bundle pricing strategy. For example, as shown in Figure 1, the retailer can bundle two units of peaches on the 2 nd day at the price of $\$ 6$.

(2) Value of Single Fresh Products with Quality Deterioration. The biochemical and physiological changes lead to the qualitative and quantitative deterioration in fresh products, such as fruits, vegetables, and meat. Quality degradation reduces consumer acceptability as well as the value perceived by the consumers. In order to make the bundle pricing strategy efficiently, it is necessary to develop mathematical models to capture the effect of quality deterioration to the value of consumers. Intuitively, the value of the fresh products is decreased with the decaying of freshness and even drops to zero as time passes by, as shown in Figure 2. The most common method to approximate the perceived value of fresh products is to use the function of product lifecycle. The most studied model is the exponential function to capture the character of quality deterioration. According to Wang and $\mathrm{Li}$ (2012) [20], the value function is formulated as

$$
V(t)=e^{-b(t-1)},
$$

where $b$ represents the decreasing factor of the fresh product and $b>0$. A higher level of $b$ demonstrates a quicker deterioration rate.

(3) Reservation Prices of Bundle of Multiple Fresh Products with Quality Deterioration. Following Stigler (1963), we first assume that customer demand information is captured by a

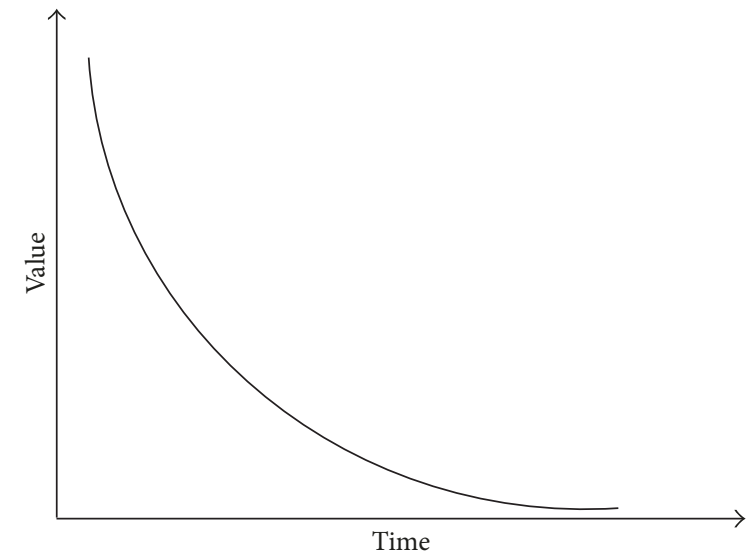

FIgUre 2: The value of fresh products in the life cycle.

vector of reservation prices of the items that go into a bundle [1]. Reservation prices have been widely used in the literature to develop customized pricing models [21]. It is regarded as the consumer's upper bound of willingness to pay for one product. The reservation prices can be fixed or generated by some sort of valuation distribution. For a bundle with multiple fresh products, the reservation prices are decreasing with the quality deterioration and also follow the law of diminishing marginal utility. Let $R_{i 11}$ be the reservation price of consumer $i$ for one unit fresh product at the first time period, which is the freshest time. $R_{i j t}$ is the reservation price of consumer $i$ to a bundle consisting $j$ unit fresh products at time $t$, and it could be formulated by (2), where $\beta$ is the marginal decreasing rate of multiple products.

$$
\begin{aligned}
R_{i j t} & =\left[j R_{i 11}-\beta(j-1)^{2}\right] V(t) \\
& =\left[j R_{i 11}-\beta(j-1)^{2}\right] e^{-b(t-1)} .
\end{aligned}
$$

(4) Customer Decisions Rules. Customers' purchasing decisions are determined by their consumer surplus, which means the difference between the total reservation price for a product (bundle) and the price they pay [5]. Customers would prefer a product (bundle) under two conditions: (1) 
individual rationality constraint, which means a product may only be bought if its surplus to consumer is greater than 0 ; (2) compatibility constraint, which indicates a consumer will select a product if it has the highest surplus. The retailer has to consider consumers' optimal decision rules, which appear as constraints in the retailer's optimization problem [16].

A complete list of parameters and variables is shown as follows.

\section{Definitions of the Parameters and Variables Used in the Model}

$I$ : Number of consumers

$i$ : Indices of consumers

$J$ : Maximum number of products, $J$, within a bundle

$j$ : Indices of bundles with $j$ units of fresh products in it

$T$ : Total life cycle period of fresh products

$t$ : Indices of life cycle period of fresh product, which is set from 1

$c_{j}$ : Cost of creating a bundle of $j$ goods. This may include the sum of marginal production cost, transaction cost, packaging cost, and so on

$R_{i j t}$ : Reservation price of consumer $i$ to bundle $j$ at time $t$. It is decreasing with time and number of items in the bundle. Particularly, $R_{i 11}$ represents the reservation price of consumer $i$ for one unit fresh product at the 1st time period

$\beta$ : Marginal decreasing rate of multiple products

$b$ : The deterioration rate of the fresh product.

\section{Decision Variables or Intermediate Variables}

$P_{j t}$ : Price of a bundle with $j$ products to be sold at time $t$

$Y_{j t}$ : The decision variable which equals 1 if the retailer chooses to offer the bundle of $j$ goods on the menu, and 0 otherwise

$X_{i j t}$ : The decision variables which equal 1 if consumer $i$ chooses to buy the bundle of $j$ units of goods at time $t$

$S_{i}$ : Consumer is surplus for the bundle she chooses.

3.2. Model Formulation. In this section, we formulate the optimal bundling and pricing problem for homogeneous fresh products. The seller providers $J$ units of fresh goods to $I$ consumers within the life cycle of fresh products $T$. The model is developed from the seller's perspective to optimize the profit while customers maximize their surplus. The problem for the seller is deciding how many goods to be included in each bundle at a specific time and how to price these bundles to maximize his profit, subject to a set of consumers' individual rationality and compatibility constraints. According to the basic notations defined in Section 3.1, we formulate the bundle pricing problem for fresh products as a nonlinear mixed integer programming model. The primal problem is given by IP.

\section{Primal Problem IP}

$$
\begin{aligned}
& \max \sum_{i=1}^{i} \sum_{j=1}^{j} \sum_{T=1}^{T}\left(P_{j t}-c_{j}\right) X_{i j t}, \\
& \text { s.t. } \quad S_{i}=\sum_{j=1}^{J} \sum_{t=1}^{T}\left(R_{i j t}-P_{j t}\right) X_{i j t}, \quad i=1, \ldots, I, \\
& S_{i} \geq\left(R_{i j t}-P_{j t}\right) Y_{j t} \text {, } \\
& i=1, \ldots, I ; j=1, \ldots, J ; t=1, \ldots, T, \\
& \left(R_{i j t}-P_{j t}\right) X_{i j t} \geq 0 \text {, } \\
& i=1, \ldots, I ; j=1, \ldots, J ; t=1, \ldots, T, \\
& R_{i j t}=\left[j R_{i 11}-\beta(j-1)^{2}\right] \cdot e^{-b(t-1)}, \\
& \sum_{j=1}^{J} \sum_{t=1}^{T} X_{i j t} \leq 1, \quad i=1, \ldots, I, \\
& \sum_{j=1}^{J} Y_{j t} \leq 1, \quad t=1,2, \ldots, T, \\
& X_{i j t} \leq Y_{j t}, \\
& i=1, \ldots, I ; j=1, \ldots, J ; t=1, \ldots, T, \\
& S_{i} \geq 0, \quad i=1, \ldots, I, \\
& P_{j t} \geq 0, \quad j=1, \ldots, J ; t=1, \ldots, T, \\
& X_{i j t}=0 \text { or } 1 \text {, } \\
& i=1, \ldots, I ; j=1, \ldots, J ; t=1, \ldots, T, \\
& Y_{j t}=0 \text { or } 1, \quad j=1, \ldots, J ; t=1, \ldots, T .
\end{aligned}
$$

The objective function (3) maximizes the total profits of the retailer. This is calculated by summing the profit obtained from each customer minus the cost of the bundle. Constraints (4) and (5) define consumer surplus of a bundle and also ensure that each customer maximizes her surplus $S_{i}$ when making her choice. This is the compatibility constraint which guarantees the final consumer surplus obtained from her choice of bundle is no less than the consumer surplus from any other bundle. Constraint (6) represents the individual rational constraint and ensures that the consumer will choose a bundle only if her surplus on this bundle is nonnegative. Constraint (7) calculates the reservation prices of consumer $i$ for bundle $j$ at time $t$. Constraint (8) ensures that each customer will purchase no more than one bundle. Constraint (9) ensures that the retailer will provide only one bundle at each time period. Constraint (10) ensures that only if the retailer offers the bundle can customers buy it. Constraints (11) and (12) are nonnegativity constraints for consumer 
surplus and bundle price. Constraint (13) enforces the integer property of the decision variables with respect to consumer purchases, and constraint (14) enforces the integer property of the decision variables with respect to bundle offerings.

3.3. Model Conversion. Due to the complication of the mixed integer nonlinear programming model, we can hardly solve it. In this paper we convert the model into a mixed integer linear programming model by adding auxiliary decision variables and by using the big $M$ method. The big $M$ method, as one of regular and effective ways to handle the nonlinear integer optimization, has been adopted widely to linearize the nonlinear mixed integer decision variables and convert the original optimization into a linear one [22].

Let $K_{i j t}=P_{j t} X_{i j t}, L_{j t}=P_{j t} Y_{j t}$, and by using the big $M$ method, the original model (IP) is converted into a new model (CP). The objective function of IP is converted into function (3.1) in CP, and the constraints (3.2)-(3.4) are restrictions to guarantee the value of $K_{i j t}$ to be equal to $P_{j t} X_{i j t}$. The constraint (4) in IP is converted into (4.1) in CP. The constraint (5) in IP is converted into (5.1), and constraints (5.2) $-(5.4)$ can ensure $L_{j t}=P_{j t} Y_{j t}$. Formulation (15) determines the value of big number $M$ according to the character of the model. Constraints (16) and (17) are nonnegative constraints of new variables $K_{i j t}$ and $L_{j t}$.

After conversion, the model can be solved by CPLEX. The detailed code of CPLEX is omitted, and we will test the model through numerical experiments in the following section.

\section{Problem CP}

$$
\begin{aligned}
& \max \sum_{t=1}^{T} \sum_{i=1}^{I} \sum_{j=1}^{J}\left(K_{i j t}-c_{j} X_{i j t}\right), \\
& \text { s.t. } K_{i j t}-M\left(1-X_{i j t}\right) \leq p_{j t} \text {, } \\
& i=1, \ldots, I ; j=1, \ldots, J ; t=1, \ldots, T, \\
& K_{i j t}+M\left(1-X_{i j t}\right) \geq p_{j t}, \\
& i=1, \ldots, I ; j=1, \ldots, J ; t=1, \ldots, T, \\
& K_{i j t}-M X_{i j t} \leq 0 \text {, } \\
& i=1, \ldots, I ; j=1, \ldots, J ; t=1, \ldots, T, \\
& S_{i}=\sum_{j=1}^{J} \sum_{t=1}^{T}\left(R_{i j t} X_{i j t}-K_{i j t}\right), \quad i=1, \ldots, I, \\
& S_{i} \geq R_{i j t} Y_{j t}-L_{j t} \text {, } \\
& i=1, \ldots, I ; j=1, \ldots, J ; t=1, \ldots, T \text {, } \\
& L_{j t}-M\left(1-Y_{j t}\right) \leq P_{j t}, \\
& j=1, \ldots, J ; t=1, \ldots, T, \\
& L_{j t}+M\left(1-Y_{j t}\right) \geq P_{j t}, \\
& j=1, \ldots, J ; t=1, \ldots, T,
\end{aligned}
$$

$$
\begin{aligned}
& L_{j t}-M Y_{j t} \leq 0, \quad j=1, \ldots, J ; t=1, \ldots, T, \\
& R_{i j t} X_{i j t}-K_{i j t} \geq 0 \text {, } \\
& i=1, \ldots, I ; j=1, \ldots, J ; t=1, \ldots, T, \\
& R_{i j t}=\left[j R_{i 11}-\beta(j-1)^{2}\right] \cdot e^{-b(t-1)}, \\
& i=1, \ldots, I ; j=1, \ldots, J ; t=1, \ldots, T, \\
& \sum_{j=1}^{J} \sum_{t=1}^{T} X_{i j t} \leq 1, \quad i=1, \ldots, I, \\
& \sum_{j=1}^{J} Y_{j t} \leq 1, \quad t=1,2, \ldots, T, \\
& X_{i j t} \leq Y_{j t} \\
& i=1, \ldots, I ; j=1, \ldots, J ; t=1, \ldots, T, \\
& S_{i} \geq 0, \quad i=1, \ldots, I, \\
& P_{j t} \geq 0, \quad j=1, \ldots, J ; t=1, \ldots, T, \\
& X_{i j t}=0 \text { or } 1 \text {, } \\
& i=1, \ldots, I ; j=1, \ldots, J ; t=1, \ldots, T, \\
& Y_{j t}=0 \text { or } 1, \quad j=1, \ldots, J ; t=1, \ldots, T, \\
& M=10 \sum_{j=1}^{J} c_{j}, \\
& K_{i j k} \geq 0, \\
& i=1, \ldots, I ; j=1, \ldots, J ; t=1, \ldots, T, \\
& L_{j t} \geq 0, \quad j=1, \ldots, J ; t=1, \ldots, T .
\end{aligned}
$$

\section{Numerical Experiments and Sensitivity Analysis}

In this section we study the effectiveness of the proposed model through a couple of numerical experiments.

\subsection{The Data Sets}

(1) Reservation Prices. Reservation prices have been widely used in literature to develop customized pricing models [13]. In this study, the customers' reservation prices for one unit of fresh product at beginning of the selling season $R_{i 11}$ should be set firstly. Following Wu et al. (2008) [16], we assume $R_{i 11}$ is normally distributed, $R_{i 11} \sim U\left(r_{l}^{0}, r_{u}^{0}\right)$. Here, $r_{l}^{0}$ and $r_{u}^{0}$ are the lower and upper bounds of customers' reservation prices. According to Jiang et al. (2011) [5], the relationship between price, cost, and the highest reservation price is $r_{u}^{0}=2 p-c$, where $p$ and $c$ are posted price and cost of the product. Then the upper bound of reservation price can be derived. As for the lower bound of the reservation price, let $r_{l}^{0}=(1-\lambda) r_{u}^{0}$, 
TABLE 1: Base values of parameters.

\begin{tabular}{lcccccc}
\hline$I$ & $J$ & $T$ & $c_{j}(\$)$ & $R_{i 11}(\$)$ & $\beta$ & $b$ \\
\hline 10 & 10 & 6 & $4 j$ & $U(6,12)$ & 0.5 & 0.04 \\
\hline
\end{tabular}

TABLE 2: An Example of bundle pricing decisions with quality deterioration.

\begin{tabular}{|c|c|c|c|c|c|c|c|c|}
\hline \multicolumn{6}{|c|}{ Bundle strategy } & \multicolumn{3}{|c|}{ Unbundle strategy } \\
\hline$t$ & $\begin{array}{c}\text { BS } \\
\text { (\#unit) }\end{array}$ & $\begin{array}{c}\text { BP } \\
\text { (\$/bundle) }\end{array}$ & $\begin{array}{l}\text { BP/BS } \\
\text { (\$/unit) }\end{array}$ & $\begin{array}{l}\text { Retailer profit } \\
(\$)\end{array}$ & $\begin{array}{l}\text { Consumer } \\
\text { surplus }(\$)\end{array}$ & $\begin{array}{l}\text { Price } \\
\text { (\$/unit) }\end{array}$ & $\begin{array}{l}\text { Retailer profit } \\
(\$)\end{array}$ & $\begin{array}{l}\text { Consumer } \\
\text { surplus (\$) }\end{array}$ \\
\hline 1 & 8 & 60.9 & 7.61 & \multirow{6}{*}{156.58} & \multirow{6}{*}{34.06} & 9.28 & \multirow{6}{*}{36.97} & \multirow{6}{*}{11.44} \\
\hline 2 & 6 & 47.8 & 7.97 & & & 8.92 & & \\
\hline 3 & 2 & 16.7 & 8.35 & & & 8.57 & & \\
\hline 4 & 1 & 8.2 & 8.20 & & & 7.63 & & \\
\hline 5 & 7 & 46.97 & 6.71 & & & 6.94 & & \\
\hline 6 & 9 & 51.9 & 5.77 & & & 6.02 & & \\
\hline
\end{tabular}

$\lambda \in[0,1]$. Here $\lambda$ represents the differences between the lowest and highest reservation prices. A higher level of $\lambda$ means a higher level of heterogeneity in consumers' valuation of the product. Taking the bundle case given in Figure 1 as an example, the price of each unit of peach on the 1st day is $\$ 8$, and the cost is $\$ 4$. We found $r_{u}^{0}=2 p-c=12$ and let $\lambda=0.5$; then $r_{l}^{0}=6, R_{i 11} \sim U(6,12)$.

(2) Setting of Parameters. Let the maximum number of bundle $J=10$, and the number of customers $I=10$ in the base experiment. The life cycle time of the fresh products $T$ is set to be 6 , which also means the retailer has 6 decision points to launch bundling strategies to promote sales. The cost of each unit of fresh product is set to be $\$ 4$. Table 1 gives the setting of parameters in the basic example.

4.2. Numerical Results. We use the basic values shown in Table 1 to give an overview of the proposed model for bundling fresh products with quality deterioration. Three indexes are used to show the characteristics of bundles, namely, bundle size (BS, number of items within a bundle), bundle price (BP), and unit product price of a bundle (BP/BS). We also list the results of unbundle strategy, which means in each period the fresh products are sold individually. The results are shown in Table 2 and characteristics of bundle and unbundle strategies in different time periods are compared. Managerial implications are as follows. (1) It is clear that, by using bundle strategy, the retailer profit and consumer surplus are both increased. It is because a bundle with proper price can stimulate consumers to purchase more products. (2) At the beginning of the life cycle, it is better to set a larger-size bundle with a relative lower unit price than the individual price under unbundle strategy ("larger-size \& lower-price"). It can be explained that consumers prefer fresh products and an effective bundle at the beginning of product life cycle could bring a higher consumer surplus and consequently increase retailer profit. (3) At the end of life cycle, because the deterioration degree is increased, both the bundle size and bundle price have to be set at a lowest level strategy ("larger-size \& lowest-price").
4.3. Sensitivity Analysis. In this section, we investigate how parameters variations affect the bundling strategies. We first study the impacts of changes in the deterioration rate of fresh products. Then changes in the range of customer reservation price distribution are examined subsequently.

(1) Deterioration Rate Variation. The parameter $b$ represents the decreasing factor of the fresh product and $b>0$. A higher level of $b$ demonstrates a faster deterioration rate. We now set $b$ as $0.01,0.04$, and 0.07 . The results are listed in Table 3 . It indicates that (1) regardless of the change in $b$ the retailer can still choose to use "larger-size \& lower-price" and "larger-size \& lowest-price" strategies at the beginning and the end of the life cycle, respectively. (2) As the deterioration rate increases, both the bundle size and unit product price at the end of life cycle are shrunk. It is because that the consumers' value of the product with quality deterioration will drop down shapely. A larger-size bundle at the end of life cycle can hardly derive consumer surplus. Consequently, a relatively smaller size bundle will be preferred if the quality decays faster.

(2) Range Variation of Reservation Prices. The range $\lambda$ represents the differences between the lowest and highest reservation prices. A higher level of $\lambda$ means a higher level of heterogeneity in consumer valuation on the product, as well as a lower level of customer consumption level [16]. The effect of changing in $\lambda$ on the bundle pricing problem is shown in Table 4. It shows that (1) the "larger-size \& lower-price" and "larger-size \& lowest-price" strategies are still useful at the beginning and the end of the life cycle, respectively. (2) However, under the scenario of lower level $\lambda$, the bundle size is relatively smaller, but the unit product price is a little bit higher. The reason lies in the fact that a lower level $\lambda$ represents a higher consumption level and consumers are almost homogeneous. Consequently, the prices can be set at a high level. But a smaller bundle size is more preferred.

(3) Marginal Decreasing Rate Variation for Multiple Products. Intuitively, for a bundle with multiple homogeneous fresh products, its value to the consumer will follow the rule of 
TABLE 3: Effect of deterioration rate variation on bundle pricing decisions.

\begin{tabular}{|c|c|c|c|c|c|c|c|c|c|}
\hline \multirow[b]{2}{*}{$t$} & \multicolumn{3}{|c|}{$b=0.01$} & \multicolumn{3}{|c|}{$b=0.04$} & \multicolumn{3}{|c|}{$b=0.07$} \\
\hline & $\begin{array}{c}\text { BS } \\
\text { (\#unit) }\end{array}$ & $\begin{array}{c}\text { BP } \\
\text { (\$/bundle) }\end{array}$ & $\begin{array}{c}\text { BP/BS } \\
\text { (\$/unit) }\end{array}$ & $\begin{array}{c}\text { BS } \\
\text { (\#unit) }\end{array}$ & $\begin{array}{c}\text { BP } \\
\text { (\$/bundle) }\end{array}$ & $\begin{array}{c}\text { BP/BS } \\
\text { (\$/unit) }\end{array}$ & $\begin{array}{c}\text { BS } \\
\text { (\#unit) }\end{array}$ & $\begin{array}{c}\text { BP } \\
\text { (\$/bundle) }\end{array}$ & $\begin{array}{c}\text { BP/BS } \\
\text { (\$/unit) }\end{array}$ \\
\hline 1 & 8 & 60.6 & 7.58 & 8 & 60.9 & 7.61 & 8 & 59.6 & 7.45 \\
\hline 2 & 6 & 49.2 & 8.20 & 6 & 47.8 & 7.97 & 2 & 16.8 & 8.42 \\
\hline 3 & 2 & 17.7 & 8.85 & 2 & 16.7 & 8.35 & 5 & 37.4 & 7.48 \\
\hline 4 & 6 & 48.1 & 8.02 & 1 & 8.2 & 8.20 & 6 & 39.8 & 6.64 \\
\hline 5 & 10 & 65.1 & 6.51 & 7 & 46.97 & 6.71 & 1 & 7.0 & 7.01 \\
\hline 6 & 9 & 61.3 & 6.81 & 9 & 51.9 & 5.77 & 3 & 20.5 & 6.83 \\
\hline
\end{tabular}

TABLE 4: Effect of range variation of reservation prices on bundle pricing decisions.

\begin{tabular}{|c|c|c|c|c|c|c|c|c|c|}
\hline \multirow[b]{2}{*}{$t$} & \multicolumn{3}{|c|}{$\lambda=0.2$} & \multicolumn{3}{|c|}{$\lambda=0.5$} & \multicolumn{3}{|c|}{$\lambda=0.8$} \\
\hline & $\begin{array}{c}\text { BS } \\
\text { (\#unit) }\end{array}$ & $\begin{array}{c}\text { BP } \\
\text { (\$/bundle) }\end{array}$ & $\begin{array}{c}\text { BP/BS } \\
\text { (\$/unit) }\end{array}$ & $\begin{array}{c}\text { BS } \\
\text { (\#unit) }\end{array}$ & $\begin{array}{c}\text { BP } \\
\text { (\$/bundle) }\end{array}$ & $\begin{array}{c}\text { BP/BS } \\
\text { (\$/unit) }\end{array}$ & $\begin{array}{c}\text { BS } \\
\text { (\#unit) }\end{array}$ & $\begin{array}{c}\text { BP } \\
\text { (\$/bundle) }\end{array}$ & $\begin{array}{c}\text { BP/BS } \\
\text { (\$/unit) }\end{array}$ \\
\hline 1 & 8 & 60.9 & 7.61 & 8 & 60.9 & 7.61 & 9 & 65.5 & 7.28 \\
\hline 2 & 4 & 35.0 & 8.74 & 6 & 47.8 & 7.97 & 4 & 33.9 & 8.48 \\
\hline 3 & 4 & 33.6 & 8.40 & 2 & 16.7 & 8.35 & 4 & 32.6 & 8.15 \\
\hline 4 & 1 & 9.1 & 9.07 & 1 & 8.2 & 8.20 & 9 & 57.4 & 6.38 \\
\hline 5 & 3 & 23.34 & 7.78 & 7 & 46.97 & 6.71 & 10 & 57.5 & 5.75 \\
\hline 6 & 5 & 34.25 & 6.85 & 9 & 51.9 & 5.77 & 10 & 53.5 & 5.35 \\
\hline
\end{tabular}

TABLE 5: Effect of marginal decreasing rate variation for multiple products on bundle pricing decisions.

\begin{tabular}{|c|c|c|c|c|c|c|c|c|c|}
\hline \multirow[b]{2}{*}{$t$} & \multicolumn{3}{|c|}{$\beta=0.2$} & \multicolumn{3}{|c|}{$\beta=0.5$} & \multicolumn{3}{|c|}{$\beta=0.8$} \\
\hline & $\begin{array}{c}\text { BS } \\
\text { (\#unit) }\end{array}$ & $\begin{array}{c}\text { BP } \\
\text { (\$/bundle) }\end{array}$ & $\begin{array}{c}\text { BP/BS } \\
\text { (\$/unit) }\end{array}$ & $\begin{array}{c}\text { BS } \\
\text { (\#unit) }\end{array}$ & $\begin{array}{c}\text { BP } \\
\text { (\$/bundle) }\end{array}$ & $\begin{array}{c}\mathrm{BP} / \mathrm{BS} \\
\text { (\$/unit) }\end{array}$ & $\begin{array}{c}\text { BS } \\
\text { (\#unit) }\end{array}$ & $\begin{array}{c}\text { BP } \\
\text { (\$/bundle) }\end{array}$ & $\begin{array}{c}\mathrm{BP} / \mathrm{BS} \\
\text { (\$/unit) }\end{array}$ \\
\hline 1 & 10 & 86.5 & 8.65 & 8 & 60.9 & 7.61 & 6 & 43.5 & 7.26 \\
\hline 2 & 4 & 33.9 & 8.48 & 6 & 47.8 & 7.97 & 4 & 32.0 & 7.99 \\
\hline 3 & 2 & 17.0 & 8.50 & 2 & 16.7 & 8.35 & 2 & 16.4 & 8.20 \\
\hline 4 & 6 & 48.18 & 8.03 & 1 & 8.2 & 8.20 & 3 & 23.2 & 7.72 \\
\hline 5 & 10 & 66.8 & 6.68 & 7 & 46.97 & 6.71 & 3 & 22.1 & 7.38 \\
\hline 6 & 10 & 62.0 & 6.20 & 9 & 51.9 & 5.77 & 3 & 21.2 & 7.05 \\
\hline
\end{tabular}

diminishing marginal utility. Here, we use $\beta$ to demonstrate the marginal decreasing rate. Practically, it can indicate whether a fresh product is proper to bundle with too many amounts. For example, compared with the apple, the durian is definitely not appropriate to bundle with too many amounts for its particular flavor and larger-size. And it will have a higher level of $\beta$. Results of changing in $\beta$ are shown in Table 5. (1) It indicates that at the beginning and the end of life cycle, the larger-size bundles are preferred. It is consistent with the previous results. (2) However, the increase in $\beta$ will definitely drop down the bundle size, whereas the unit product price will maintain a higher level. It can be explained intuitively that a product with higher marginal decreasing rate is suited for small size bundle. And the retailer can earn profit only if the price is set at a relatively higher level.

\section{Conclusions}

This study has investigated the bundle pricing problem for homogeneous fresh products with quality deterioration. The time value of fresh products has been approximated by using a lifecycle function, based on which the consumer reservation price has been formulated. Then, we have formulated the bundle pricing problem as a nonlinear mixed integer programming model. Next, the big $M$ method has been used to linearize the nonlinear model, and the model has been converted into a linear one. Finally, we have carried out several numerical experiments to verify the efficiency and effectiveness of bundling pricing strategy. Numerical results demonstrated that the best time to bundle a larger number of fresh products was right after the beginning of the selling time and at the end of life cycle. Besides, the decrease in 
consumer heterogeneity and increase in deterioration rate would drop down the bundle size at a stable level in the whole life cycle of the fresh products. These findings can not only guide the grocery retailer to make price strategy and carry out the inventory and promotion activities on agriproducts, but also enrich the theoretical contributions in agricultural operations management.

A shortcoming of this work is lack of solution algorithm for the proposed model. We leave it in our future work. Besides, some potential research questions include the following areas. First, the combination with the technology of IOT (Internet of Things) to get the real-time data of fresh product quality is a direction to improve the practicability of the proposed model. Second, incorporating the logistics service into the proposed model is also worth further studying.

\section{Conflicts of Interest}

The authors declared that they have no conflicts of interest.

\section{Acknowledgments}

This research was supported by the China Postdoctoral Science Foundation funded project (no. 2013M541593), Jiangsu Planned Projects for Postdoctoral Research Funds (no. 1302134C), Social Science Planning Fund Program of Liaoning Province (L17BGL015, L17BJL008), the Fundamental Research Funds for the Central Universities (NAU: KYZ201663; NAU: SKTS2016038; NAU: SKYC2017007; NAU: SKYZ2017025), Jiangsu Natural Science Foundation of China (BK20160742), High Quality Engineering of Social Science Application Fund in Jiangsu (17SYC-026), and Humanity and Social Science Youth Foundation of Ministry of Education of China (17YJC630048).

\section{References}

[1] Fresh Supermarket Market Analysis and Industry Survey Report in China. Posted by BosiData on Oct. http://www.bosidata.com/news/167198KQTU.html [Accessed on 2017.1.12], 2016.

[2] Y. Yu and T. Xiao, "Pricing and cold-chain service level decisions in a fresh agri-products supply chain with logistics outsourcing," Journal of Industrial Engineering, vol. 111, pp. 56-66, 2017.

[3] Y. Qin, J. Wang, and C. Wei, "Joint pricing and inventory control for fresh produce and foods with quality and physical quantity deteriorating simultaneously," International Journal of Production Economics, vol. 152, pp. 42-48, 2014.

[4] G. J. Stigler, "United States v. Loew's inc.: a note on blockbooking," The Supreme Court Review, vol. 1963, pp. 152-157, 1963.

[5] Y. Jiang, J. Shang, C. F. Kemerer, and Y. Liu, "Optimizing E-tailer profits and customer savings: pricing multistage customized online bundles," Marketing Science, vol. 30, no. 4, pp. 737-752, 2011.

[6] A. Cataldo and J.-C. Ferrer, "Optimal pricing and composition of multiple bundles: a two-step approach," European Journal of Operational Research, vol. 259, no. 2, pp. 766-777, 2017.

[7] S. Mayer, R. Klein, and S. Seiermann, "A simulation-based approach to price optimisation of the mixed bundling problem with capacity constraints," International Journal of Production Economics, vol. 145, no. 2, pp. 584-598, 2013.

[8] X. Wang, Z. P. Fan, and Z. Liu, "Optimal markdown policy of perishable food under the consumer price fairness perception," International Journal of Production Research, vol. 54, no. 19, pp. 5811-5828, 2016.

[9] G. Liu, J. Zhang, and W. Tang, "Joint dynamic pricing and investment strategy for perishable foods with price-quality dependent demand," Annals of Operations Research, vol. 226, no. 1, pp. 397-416, 2015.

[10] X. Geng, M. B. Stinchcombe, and A. B. Whinston, "Bundling information goods of decreasing value," Management Science, vol. 51, no. 4, pp. 662-667, 2005.

[11] P. J. Liu, K. L. Haws, C. Lamberton, T. H. Campbell, and G. J. Fitzsimons, "Vice-virtue bundles," Management Science, vol. 61, no. 1, pp. 204-228, 2015.

[12] M. Sheikhzadeh and E. Elahi, "Product bundling: Impacts of product heterogeneity and risk considerations," International Journal of Production Economics, vol. 144, no. 1, pp. 209-222, 2013.

[13] E. T. Bradlow and V. R. Rao, "A hierarchical Bayes model for assortment choice," Journal of Marketing Research, vol. 37, no. 2, pp. 259-268, 2000.

[14] W. Hanson and R. K. Martin, "Optimal bundle pricing," Management Science, vol. 36, no. 2, pp. 155-174, 1990.

[15] R. Venkatesh and V. Mahajan, "The design and pricing of bundles: a review of normative guidelines and practical approaches," Handbook of Pricing Research in Marketing, pp. 232-257, 2009.

[16] S.-Y. Wu, L. M. Hitt, P.-Y. Chen, and G. Anandalingam, "Customized bundle pricing for information goods: a nonlinear mixed-integer programming approach," Management Science, vol. 54, no. 3, pp. 608-622, 2008.

[17] B. G. Hardie, E. J. Johnson, and P. S. Fader, "Modeling loss aversion and reference dependence effects on brand choice," Marketing science, vol. 12, no. 4, pp. 378-394, 1993.

[18] C.-Y. Dye and C.-T. Yang, "Optimal dynamic pricing and preservation technology investment for deteriorating products with reference price effects," Omega, vol. 62, pp. 52-67, 2016.

[19] R. Bai and G. Kendall, "A model for fresh produce shelfspace allocation and inventory management with freshnesscondition-dependent demand," INFORMS Journal on Computing, vol. 20, no. 1, pp. 78-85, 2008.

[20] X. Wang and D. Li, "A dynamic product quality evaluation based pricing model for perishable food supply chains," Omega, vol. 40, no. 6, pp. 906-917, 2012.

[21] Y. Chen and G. Iyer, "Consumer addressability and customized pricing," Marketing Science, vol. 21, no. 2, pp. 197-208, 2002.

[22] A. Schrijver, Theory of Linear and Integer Programming, John Wiley \& Sons, 1998. 


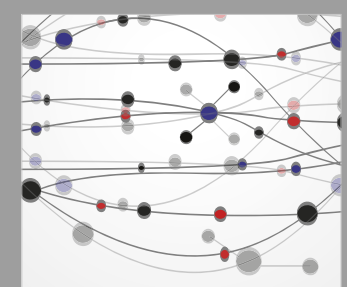

The Scientific World Journal
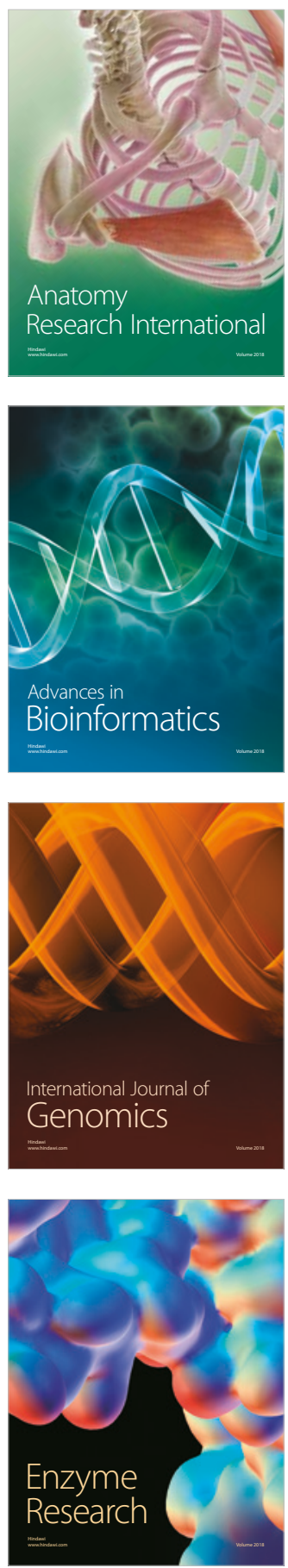
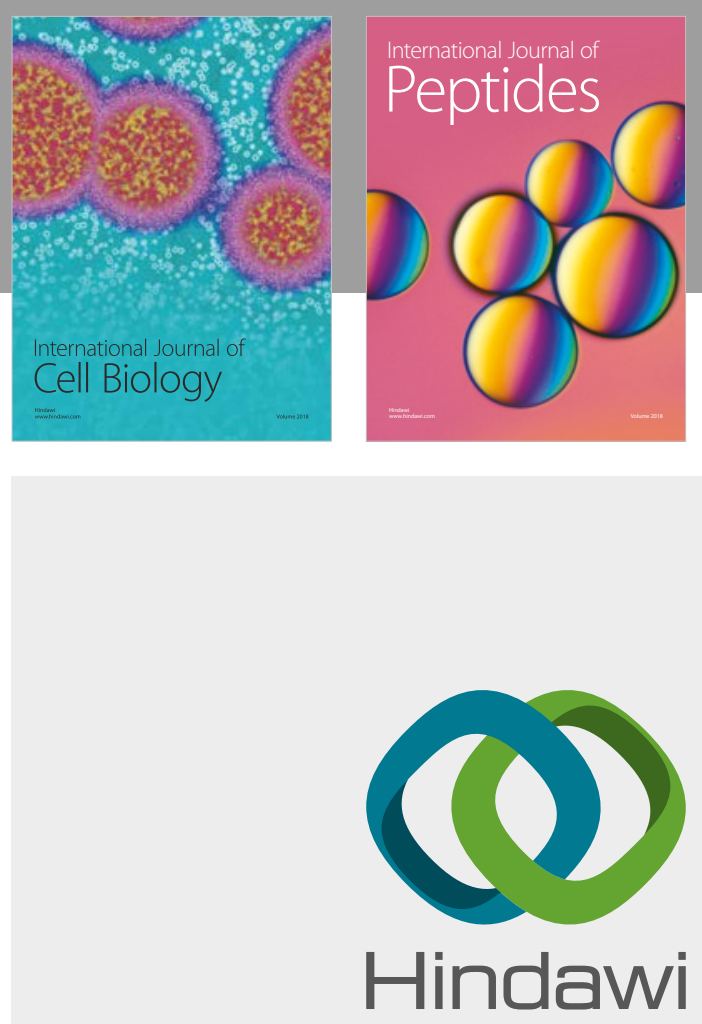

Submit your manuscripts at

www.hindawi.com
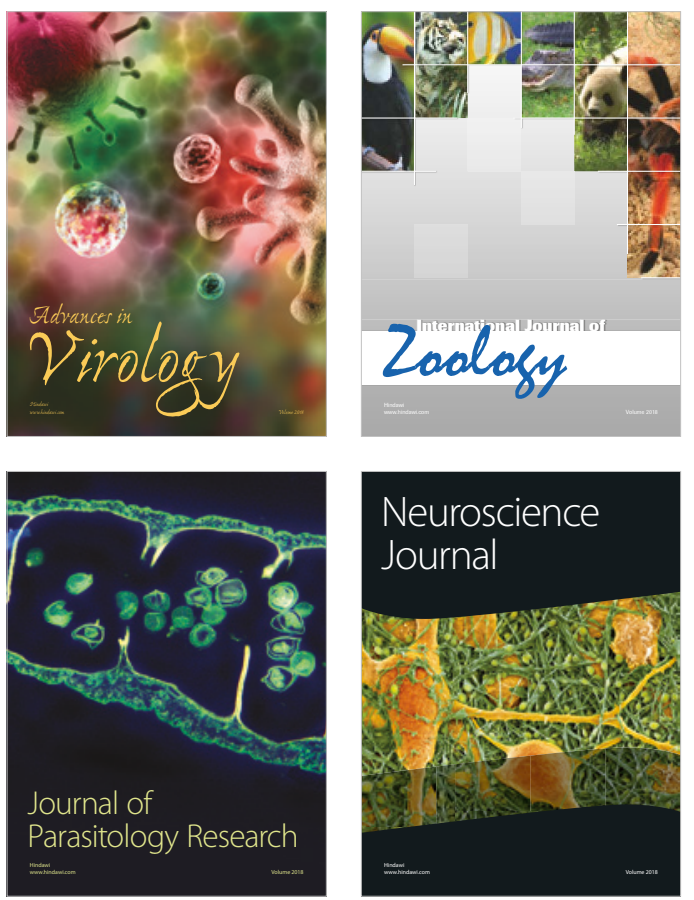
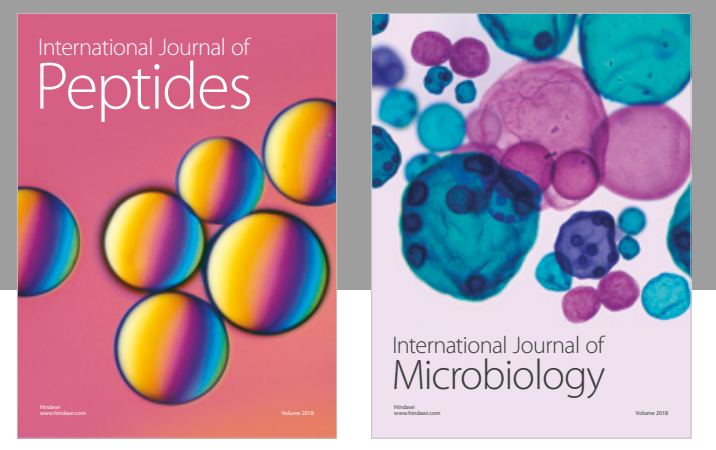

nternational Journal of Microbiology
Journal of
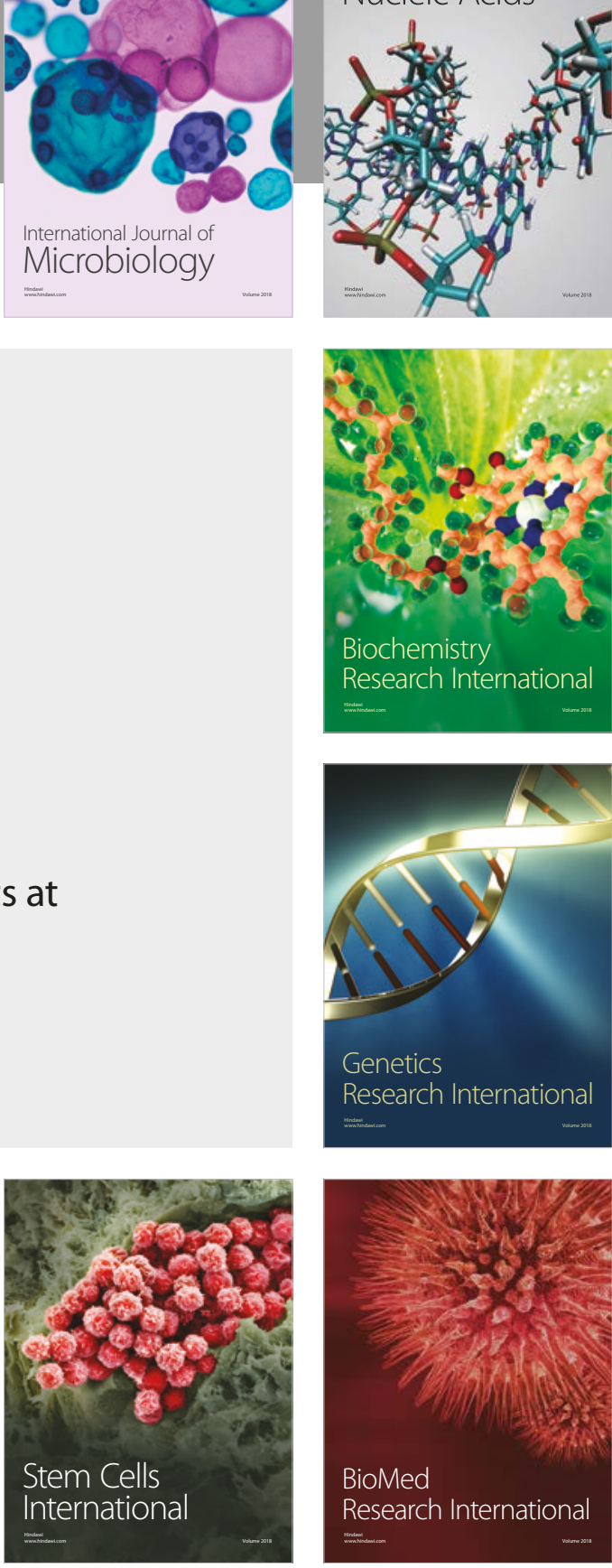
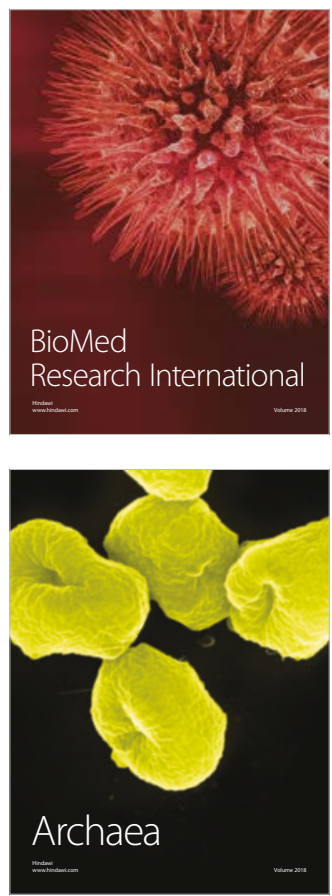